ALCHEMY Jurnal Penelitian Kimia

Laman resmi: https://jurnal.uns.ac.id/alchemy

\title{
Ion Chromatographic Method for the Simultaneous Determination of Anions and Cations in Firecrackers and Matches Samples as Known Potential Explosives
}

\author{
Muhammad Amin ${ }^{a^{*}}$ and Lee Wah Lim ${ }^{b}$ \\ ${ }^{a}$ Study Program of Chemistry Education, Faculty of Teacher Training and Education, Universitas Khairun, \\ Jalan Bandara Babullah, Akehuda, Ternate 97723, North Maluku, Indonesia \\ ${ }^{b}$ Department of Chemistry and Biomolecular Science, Faculty of Engineering, Gifu University, 1-1 \\ Yanagido, Gifu 501-1193, Japan \\ * Corresponding author \\ E-mail:muh_amin@unkhair.ac.id
}

DOI: 10.20961/alchemy.15.1.27570.138-149

Received 02 February 2019, Accepted 27 February 2019, Published 01 March 2019

\begin{abstract}
A reference ion chromatography method based on column switching has been presented for the simultaneous determining anions $\left(\mathrm{Cl}^{-}, \mathrm{ClO}_{3}{ }^{-}, \mathrm{NO}_{2}{ }^{-}, \mathrm{SO}_{4}{ }^{2-}\right.$, and $\left.\mathrm{NO}_{3}{ }^{-}\right)$and/or cations $\left(\mathrm{NH}_{4}^{+}, \mathrm{Na}^{+}, \mathrm{K}^{+}, \mathrm{Ca}^{2+}\right.$, and $\mathrm{Mg}^{2+}$ ) using one pump, one type of mobile phase, and one detector. The reference method performed anion-exchange column and cation-exchange column and arranged serially via one 10-port valve. The determination of either anions or cations in one determination system could be made by switching the valve. When the use of $1.25 \mathrm{mM}$ trimellitic acid as a mobile phase and the instrument was operated at a flow rate of $0.6 \mathrm{~mL} / \mathrm{min}$, five anions and five cations were determined on the anion-exchange column and the cationexchange column, respectively. All anions target could be determined completely within 55 minutes, whereas the cations target could be determined within 35 minutes. The calculation of limit of detection using $\mathrm{S} / \mathrm{N}=3$ was $3.85-14.10 \mu \mathrm{M}$ for anions and $2.95-10.58 \mu \mathrm{M}$ for cations. The relative standard deviations of all ions were less than $3.82 \%, 3.29 \%$, and $3.21 \%$ for retention time, peak area, and peak height, respectively. The reference method was then applied for the simultaneous determining anions and/or cations contained in firecrackers and matches samples as known potentially explosives.
\end{abstract}

Keywords: anions and cations, column switching, firecrackers, ion chromatography, matches

\section{INTRODUCTION}

Since ion chromatography (IC) method was first introduced by Small et al. in 1975, (Weiss, 1995), now become an excellent analytical tool for determining inorganic ions in forensic sciences (Doyle and McCord, 1998; Hopper et al., 2005; Feng et al., 2008; Johns et al., 2008; Meng et al., 2008), counter-terrorism (Amin, 2014; Mishra and Jaiswal, 2017), and the most application is in the environmental water monitoring (Ohta, et al., 1996; Jackson et al., 2003). A conventional, anions and cations are determined separately 
using different determination optimum conditions. And a number of published papers have been discussed for determining simultaneously both anions and cations in a one determination system due to a potential to increase the efficiency of ion chromatographic determination in a laboratory work (Jones and Tarter, 1984; Saari-Nordhaus and Anderson, 1991; Amin, et al., 2007; 2008).

Fast identification of inorganic ions in explosives materials is an important factor for counterterrorism procedures. The main analytical techniques have been used for the determination of ionic components related to explosive samples such as capillary electrophoresis (CE) (Doyle and Mccord, 1998), capillary zone electrophoresis (CZE) (Hopper et al., 2005; Feng et al., 2008), and IC (Johns et al., 2008). CE promises faster separation and low cost of operation. However, it offered poorer detection sensitivity in their analysis. IC is currently used in many wide ranges of application including the detection of cations and anions presented in explosives and potentially explosives samples such as firecrackers and fireworks (Amin, 2014).

Referring to the recent development, there are at least two approaches known for determining simultaneously anions and cations in one arrangement determination system, namely (1) using one column which allows partially determining simultaneously anions and cations (Iskandarani and Miller, 1985; Jones and Tarter, 1984; Saari-Nordhaus and Anderson, 1991), and (2) using two analytical separators parallelly- and seriesly-connected with or without column switching (Amin, et al., 2007; 2008). For the latter, in which there is no column switching, an appropriate mobile phase should be considered for the simultaneous determining both cations and anions. However, the obtained anions and cations peaks often overlapped; therefore, it is not a promising method anymore. In 2008, Meng et al. suggested an alternative method for the simultaneously determining cations and anions normally found in explosive residues samples which can be achieved by connecting directly cation-exchange/anion-exchange analytical columns with the series arrangement. However, it gave the poor selectivity of anions and not satisfactory baseline separation for anion peaks under the chosen mobile phase (Meng et al., 2008).

The most advantage of the column switching method is the ability for simultaneous determining cations and anions in one determination arrangement system in terms of providing better peaks shape and selectivity without peaks overlapping. An IC method based on column switching is intended to use two columns arranged in series in a single determination system. In this case, the cation-exchange column was prepared to determine the cations concentration in the samples, while the anion-exchange column was prepared to 
determine the anions concentration. However, a switching device is surely needed to ensure the ions targets.

Inorganic compounds commonly found in explosives such as ammonium nitrate $\left(\mathrm{NH}_{4} \mathrm{NO}_{3}\right)$, potassium chlorate $\left(\mathrm{KClO}_{3}\right)$, sodium nitrate $\left(\mathrm{NaNO}_{3}\right)$, potassium perchlorate $\left(\mathrm{KClO}_{4}\right)$, and potassium nitrate $\left(\mathrm{KNO}_{3}\right)$. Potassium chlorate $\left(\mathrm{KClO}_{3}\right)$ is one of the most widely used and as dangerous oxidizers in firecracker and matches samples. The application of ion chromatography technique can be used for analyzing the ion content in explosives of both of pre- and post-blast residues. The inorganic ions such as $\mathrm{Cl}^{-}, \mathrm{ClO}_{3}{ }^{-}$, $\mathrm{NO}_{2}{ }^{-}, \mathrm{SO}_{4}{ }^{2-}, \mathrm{NO}_{3}{ }^{-}, \mathrm{NH}_{4}{ }^{+}, \mathrm{Na}^{+}, \mathrm{K}^{+}, \mathrm{Ca}^{2+}$, and $\mathrm{Mg}^{2+}$ are the ions that are very crucial and important to be detected in order to determine the type of explosives used by criminalists.

Therefore, this present study discusses the improvement of ion chromatographic method for the simultaneous determining inorganic anions particularly $\mathrm{ClO}_{3}{ }^{-}$and inorganic cations in one determination system, and its application for potentially explosive materials such as firecrackers and matches. The improved method was performed with a 10-port valve that as a key part of the method to easily switch and control the target ions and determinations.

\section{EXPERIMENTAL METHOD}

\section{Ion Chromatograph}

The ion chromatograph and the column switching performances were almost the same as the previous study (Amin et al., 2008) except for both analytical columns. The experimental setup consisted of PU-2080i HPLC pump (Jasco, Japan), 5095 loop injector model with $20-\mu \mathrm{L}$ of sample volume (Rheodyne, USA), CM 8020 detector (Tosoh, Japan), 10-port valve (Rheodyne), and computer-aided chromatography (Filcon, Japan). TSKgel IC Anion PWxl PEEK (7.5 cm x $0.46 \mathrm{~cm}$ i.d.) (Tosoh, Japan) and TSKgel IC Cation/P (15 $\mathrm{cm}$ x $0.46 \mathrm{~cm}$ i.d.) (Tosoh, Japan) analytical columns were used for anions and cations determinations, respectively.

\section{Reagents and Solutions}

The ionic liquid employed was analytical grade chemicals and were available from Nacalai Tesque in Kyoto, Japan. All standards were prepared using deionized water. First, each $50 \mathrm{mM}$ of stock standard solutions for 5 anions (chloride, chlorate, nitrite, nitrate, and sulfate) and 5 cations (sodium, ammonium, potassium, magnesium, and calcium) were prepared as individual ions standards. The calibration curves were prepared from a mixed cations standard $(0.1,0.2,0.3,0.4,0.5) \mathrm{mM}$ and mixed anions standard series $(0.1,0.2,0.3$, 
$0.4,0.5) \mathrm{mM}$ of the stock standard solutions. The trimellitic acid mobile phase was available from Wako (Osaka, Japan). Since the mobile phase could critically become an unstable solution, it was freshly prepared before the experiment.

\section{The collection, Preparation, and Treatment Samples}

The samples were collected from the firecrackers and matches powders. Firecrackers powder was obtained by removing from its packaging, while matches powder was obtained by scraping the top-end of the match, as shown in Figure 1. The samples were prepared by the following approach. Each $1.0 \mathrm{~g}$ powder sample was added to $50 \mathrm{~mL}$ of deionized water and then mixed the samples with a shake followed by centrifuging at $2000 \mathrm{rpm}$ for 15 minutes. Finally, the samples were filtered through a $0.45 \mu \mathrm{m}$ of pore size filter membrane before injection into the instrument.
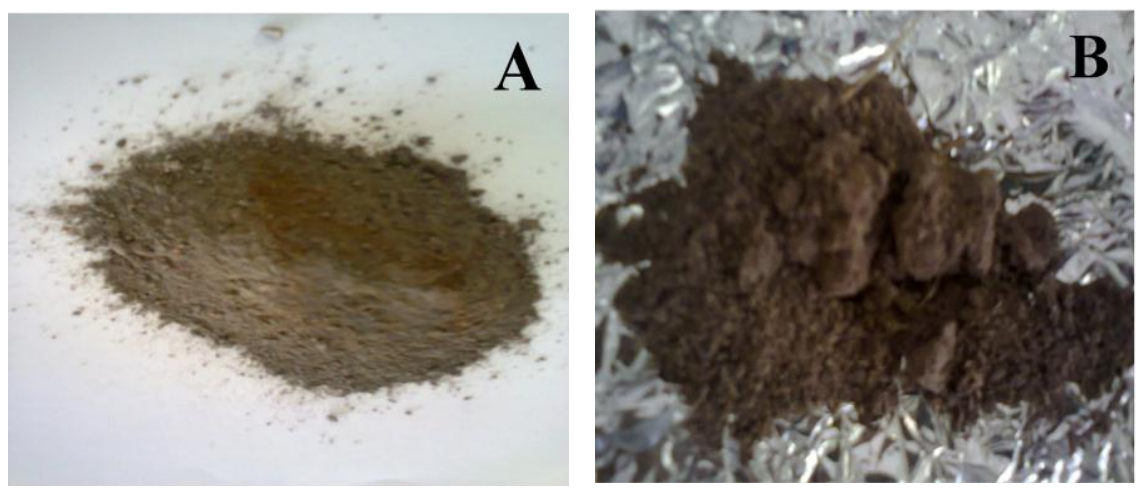

Figure 1. Powder of the real samples: firecrackers sample (A) and matches sample (B)

\section{Mobile Phase and Operating Conditions}

The mobile phase concentration used in this work was $1.25 \mathrm{mM}$ trimellitic acid. The determination conditions were under isocratic mode. Each column has a pressure limit, $8 \mathrm{MPa}$ for the anion-exchange column and $10 \mathrm{MPa}$ for the cation-exchange columns. Since the developed method used two columns connected in a series arrangement, the inlet pressure should be kept at maximum $8 \mathrm{MPa}$ by operating the flow-rate pump at 0.6 $\mathrm{mL} / \mathrm{min}$.

\section{Column Switching Performances}

Figure 2 shows the setup of the method including both ion-exchange columns positions and the 10-port valve. The improved method was performed following the procedure as follow.

In setup $A$, the eluent passed both ion-exchange columns until obtaining a straight baseline. A $20 \mu \mathrm{L}$ of anions standard volume was then injected into the instrument. The analytes containing anions and cations would arrive at the anion-exchange column, and the 
system determined the analyte anions only. While the anion-exchange column was being operated to determine anions, the other column was remained conditioned with the mobile phase. Therefore, when the valve switched to the determination of cations, a straight baseline could be quickly obtained.

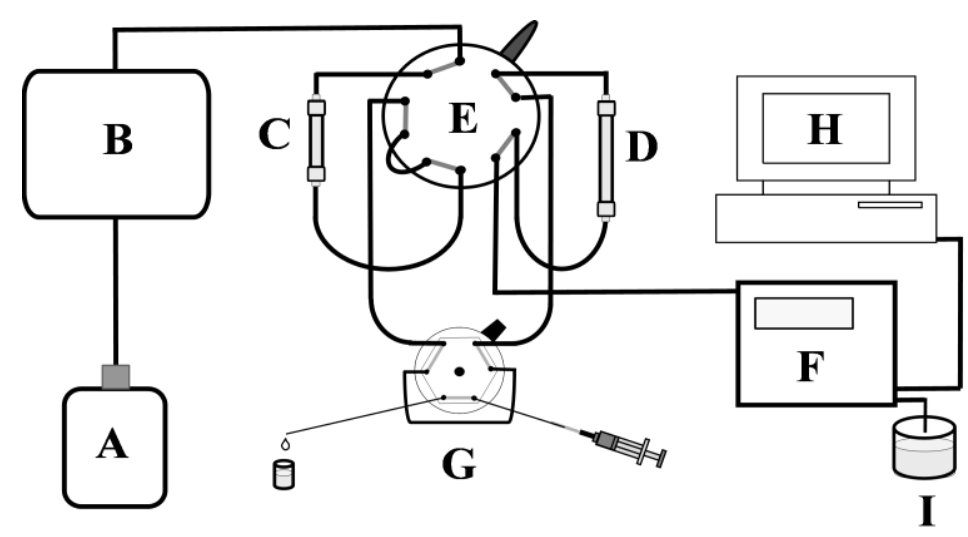

Setup I

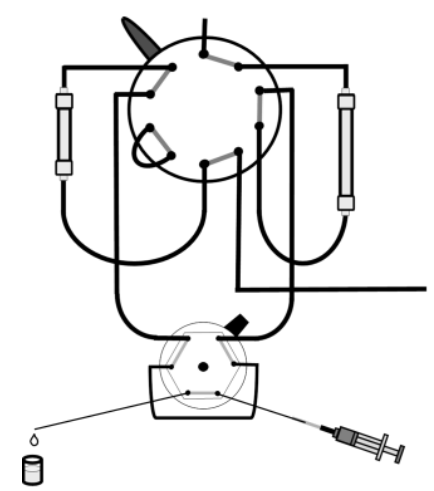

Setup II

Figure 2. The setup of the reference method with anion- and cation-exchanger connected in series arrangement via a 10-port valve. Determination of anions (setup I) and determination of cations ( exchanger, D. Cation-exchanger, E. 10-port valve. F. Conductivity, G. Sample injection, H. Data processor, I. Waste.

In setup $B$, after the valve was switched for the determination of cations, and then a $20 \mu \mathrm{L}$ of cations standard volume was injected into the instrument. The analytes containing anions and cations would arrive at the cation-exchange column, and the system determined the analyte cations only. While the cation-exchange column was being operated to determine cations, the other column was also remained conditioned with the mobile phase, so that a straight baseline could be quickly re-obtained when the valve re-switched to the determination of anions. 


\section{RESULTS AND DISCUSSION}

\section{The Effects of Trimellitic Acid Mobile Phase Concentrations}

In order to investigate the optimum of mobile phase concentration, various concentrations containing trimellitic acid was used to check the effects of the determination of anions and cations on retention time. The samples of standard for anions and cations were injected on anion-exchange and cation-exchange columns, respectively, where the concentration of trimellitic acid was in the range $1.0-2.0 \mathrm{mM}$.

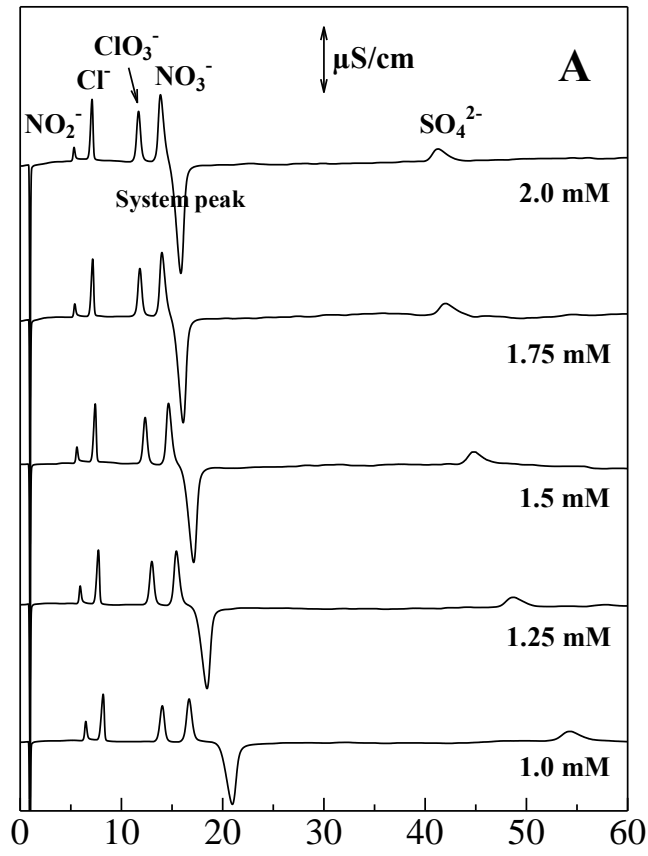

Time (minutes)

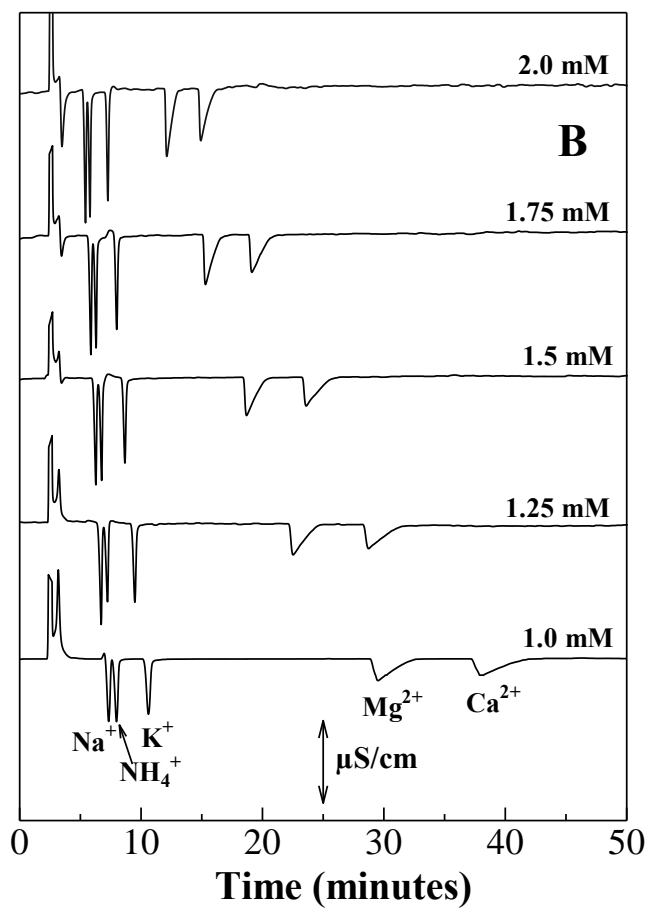

Time (minutes)

Figure 3. The differences of chromatographic profiles on the retention time, (A) for anions and (B) for cations by changing the mobile phase concentration. Mobile phase: 1.0 - 2.0 $\mathrm{mM}$ trimellitic acid. Columns: TSKgel IC Anion PWxl PEEK ( $7.5 \mathrm{~cm}$ x $0.46 \mathrm{~cm}$ i.d.) and

TSKgel IC Cation/P (15 cm x $0.46 \mathrm{~cm}$ i.d.). Flow-rate: $0.6 \mathrm{~mL} / \mathrm{min}$. Injection: $20 \mu \mathrm{L}$.

Figure 3 displays the chromatograms of five anions and five cations at different mobile phase concentrations. The mobile phase concentration increased as retention time values of both anions $\left(\mathrm{Cl}^{-}, \mathrm{ClO}_{3}{ }^{-}, \mathrm{NO}_{2}{ }^{-}, \mathrm{SO}_{4}{ }^{2-}\right.$, and $\left.\mathrm{NO}_{3}{ }^{-}\right)$and cations $\left(\mathrm{NH}_{4}{ }^{+}, \mathrm{Na}^{+}, \mathrm{K}^{+}\right.$, $\mathrm{Ca}^{2+}$, and $\mathrm{Mg}^{2+}$ ) decreased. When the concentration of the mobile phase was less than 1.25 $\mathrm{mM}$, the divalent ions $\left(\mathrm{Mg}^{2+}, \mathrm{Ca}^{2+}\right.$, and $\left.\mathrm{SO}_{4}{ }^{2-}\right)$ were retained longer. When the concentration of the mobile phase was higher than $1.25 \mathrm{mM}$, the baseline determination between $\mathrm{Na}^{+}$and $\mathrm{NH}_{4}{ }^{+}$was not achieved, and $\mathrm{NO}_{3}{ }^{-}$tends to overlap with the system peak. The system peak generally appears in the chromatogram when the analyte or solute is injected into the chromatographic system. The elution time of system peak and its size depends on the sample matrix and pH of the mobile phase (Okada and Kuwamoto, 1984). However, their capacity ratio is independent of solute injected. 

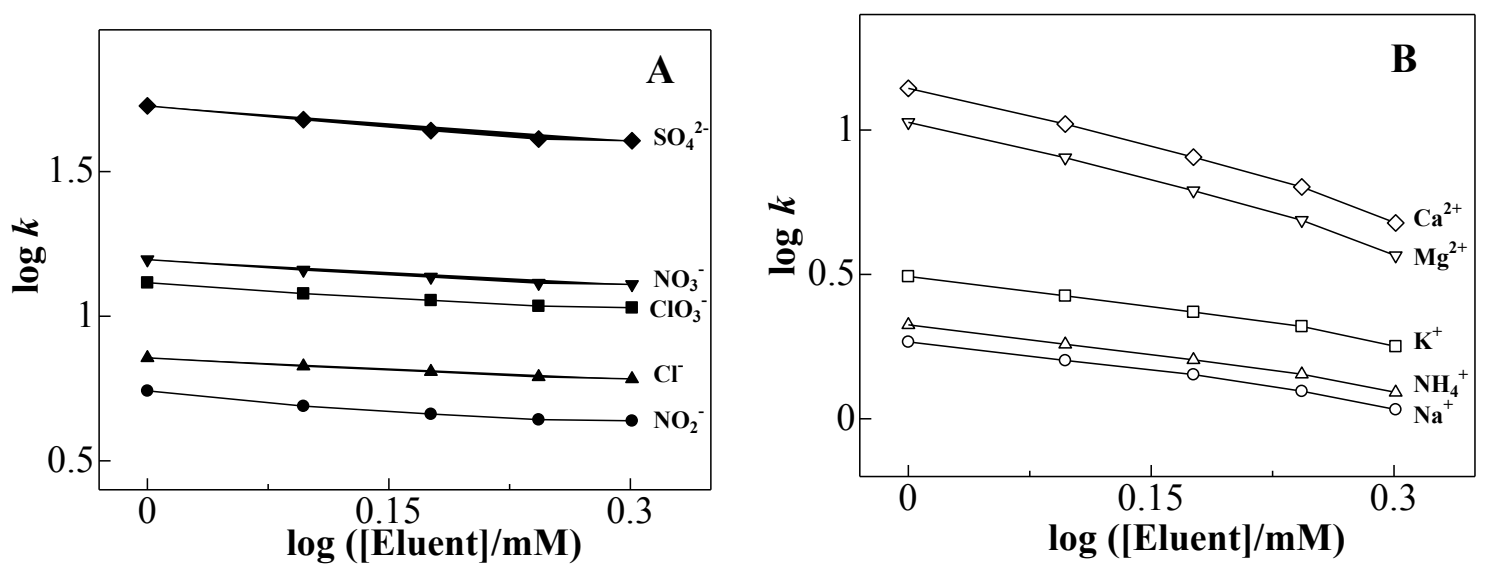

Figure 4. Effect of mobile phase concentrations on retention factors of anions and cations. Mobile phase: trimellitic acid. Plot lines: A. anions, and B. cations. Other analytical conditions, as in Figure 3.

A linear relationship between the logarithm of the mobile phase concentration (Log [Eluent]) and the logarithm of the factor of retention $(\log k)$ of anions and cations and were observed, as plotted in Figure 4. In other words, the slope values are the eluent ionic valency $(\log$ [Eluent]) and the ratio of the analyte ionic valency $(\log k)$ (Grushka and Grinberg, 2007). As illustrated in Figure 4A, the obtained slope for analyte anions were $-0.35,-0.24,-0.29,-0.29$, and -0.42 for $\mathrm{NO}_{2}{ }^{-}, \mathrm{Cl}^{-}, \mathrm{ClO}_{3}{ }^{-}, \mathrm{NO}_{3}{ }^{-}$, and $\mathrm{SO}_{4}{ }^{2-}$, respectively. Therefore, it is expected that the slope values for monovalent anions should be -0.5 and the divalent anions should be -1 . Figure $4 \mathrm{~B}$ illustrates the slopes value for cations were $-0.76,-0.76,-0.78,-1.51$, and -1.52 for $\mathrm{Na}^{+}, \mathrm{NH}_{4}{ }^{+}, \mathrm{K}^{+}, \mathrm{Mg}^{2+}$, and $\mathrm{Ca}^{2+}$, respectively. The expected slope values for mono- and divalent cations should be -1 and -2 , respectively. As the above results, it was found that the trimellitic acid mobile phase average valence was about 1.5 .

\section{The Effects of Anion- and Cation-exchange Columns Connected via 10-port Valve}

As shown in Figure 5, the anion- and cation-exchange columns are connected serially arrangement via a 10-port valve. The desired determinations could be controlled by switching the valve. It also means that the determination of anions and/or cations can be done in one chromatographic system. However, the obtained anions and cations chromatograms are independent. The five anions target $\left(\mathrm{Cl}^{-}, \mathrm{ClO}_{3}{ }^{-}, \mathrm{NO}_{2}{ }^{-}, \mathrm{SO}_{4}{ }^{2-}\right.$, and $\mathrm{NO}_{3}{ }^{-}$) could be determined completely within 55 minutes, whereas, the five cations target $\left(\mathrm{NH}_{4}{ }^{+}, \mathrm{Na}^{+}, \mathrm{K}^{+}, \mathrm{Ca}^{2+}\right.$, and $\left.\mathrm{Mg}^{2+}\right)$ could be determined within $35 \mathrm{~min}$, as displayed in Figure 5. Attention to Figure 5A, system peak appeared between $\mathrm{NO}_{3}{ }^{-}$and $\mathrm{SO}_{4}{ }^{2-}$ ions. At lower concentration of eluent $(<1.25 \mathrm{mM})$, the monovalent and divalent anions could be 
separated further from the system peak. However, the divalent anions and cations took longer analysis time.

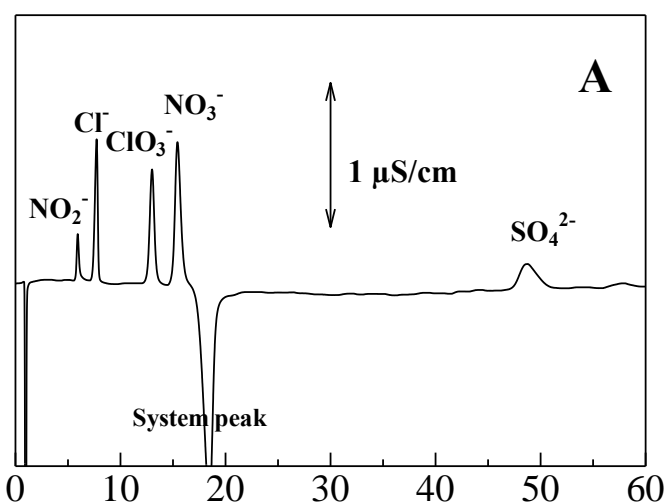

Time (minutes)

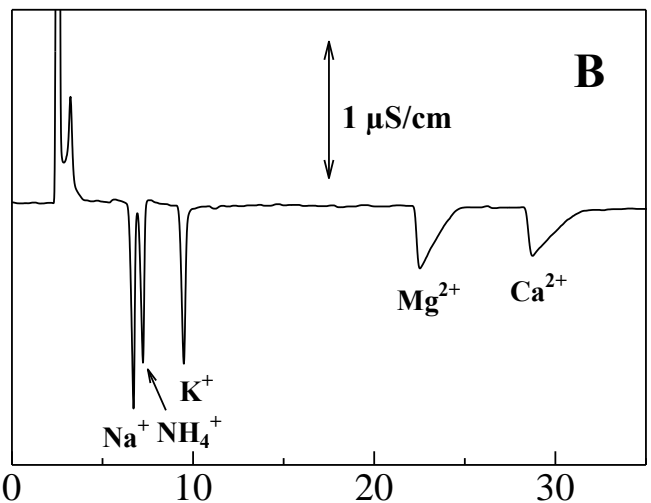

Time (minutes)

Figure 5. Determination of anions and/or cations using the column-switching method. Mobile phase: $1.25 \mathrm{mM}$ trimellitic acid. Analytes are containing $0.5 \mathrm{mM}$ of each ion. Other analytical conditions, as in Figure 3.

\section{Method Validation}

The coefficient of correlation $\left(r^{2}\right)$ for the cations and anions are listed in Table 1. Peak heights showed a good linear correlation on the range of ion concentration from 0.1 to $0.5 \mathrm{mM}$. The limit of detection (LOD) of all ions was calculated at a signal-to-noise $(\mathrm{S} / \mathrm{N})$ ratio is 3 , and the results are summarized in Table 1 . The LOD obtained by the developed method was $3.85-14.10 \mu \mathrm{M}$ for the anions and $2.95-10.58 \mu \mathrm{M}$ for the cations.

Table 1. Summarized data for LOD, $r^{2}$, and $t_{\mathrm{R}}$ of anions and cations obtained under the optimum analytical conditions, as in Figure 5.

\begin{tabular}{crrlr}
\hline \multirow{2}{*}{ Analytes } & \multicolumn{3}{c}{ LOD } & \multicolumn{3}{c}{$\begin{array}{l}\text { Coefficient } \\
\text { correlation }\end{array}$} \\
\cline { 2 - 5 }$\left(r^{2}\right)$ & $\begin{array}{l}t_{\mathrm{R}} \\
\text { (minutes) }\end{array}$ \\
\hline $\begin{array}{c}\text { Anions: } \\
\mathrm{NO}_{2}{ }^{-}\end{array}$ & 9.31 & 0.43 & 0.9954 & 5.59 \\
$\mathrm{Cl}^{-}$ & 3.85 & 0.14 & 0.9963 & 7.52 \\
$\mathrm{ClO}_{3}{ }^{-}$ & 4.28 & 0.36 & 0.9994 & 13.01 \\
$\mathrm{NO}_{3}{ }^{-}$ & 3.54 & 0.22 & 0.9998 & 15.44 \\
$\mathrm{SO}_{4}{ }^{2-}$ & 14.10 & 1.34 & 0.9928 & 48.59 \\
\hline $\mathrm{Cations}^{+}$ & & & & \\
$\mathrm{Na}^{+}$ & 2.95 & 0.07 & 0.9971 & 6.59 \\
$\mathrm{NH}_{4}{ }^{+}$ & 3.08 & 0.06 & 0.9956 & 7.24 \\
$\mathrm{~K}^{+}$ & 3.55 & 0.14 & 0.9921 & 9.52 \\
$\mathrm{Mg}^{2+}$ & 8.08 & 0.19 & 0.9935 & 22.53 \\
$\mathrm{Ca}^{2+}$ & 10.58 & 0.42 & 0.9918 & 28.58 \\
\hline
\end{tabular}

${ }^{\mathrm{a}}$ The concentration range of standard samples: 0.1 to $0.5 \mathrm{mM}$ for all ions 
Table 2 shows the repeatabilities of the signals (retention time, peak area, and peak height) of analytes (anions and cations) for seven measurements under the optimum analytical conditions described in Figure 5. The relative standard deviation (RSD) of all ions were less than $3.82 \%, 3.29 \%$, and $3.21 \%$ for retention time, peak area, and peak height, respectively. It means that these values are significantly lower than the limit of imposed.

Table 2. RSD of anions and cations under the optimum analytical conditions in Figure 5.

\begin{tabular}{clll}
\hline \multirow{2}{*}{ Analytes } & \multicolumn{3}{l}{$\mathrm{RSD}(\%), \mathrm{n}=7$} \\
\cline { 2 - 4 } & Retention time & Peak area & Peak height \\
\hline Anions: & & & \\
$\mathrm{NO}_{2}{ }^{-}$ & 1.96 & 1.93 & 1.82 \\
$\mathrm{Cl}^{-}$ & 2.78 & 2.15 & 1.94 \\
$\mathrm{ClO}_{3}{ }^{-}$ & 2.83 & 1.98 & 2.80 \\
$\mathrm{NO}_{3}{ }^{-}$ & 3.05 & 2.84 & 3.22 \\
$\mathrm{SO}_{4}{ }^{2-}$ & 3.82 & 3.21 & 3.29 \\
\hline Cations: & & \\
$\mathrm{Na}^{+}$ & 1.59 & 2.16 & 1.34 \\
$\mathrm{NH}_{4}{ }^{+}$ & 1.82 & 1.89 & 1.78 \\
$\mathrm{~K}^{+}$ & 1.92 & 2.72 & 2.92 \\
$\mathrm{Mg}^{2+}$ & 2.74 & 2.98 & 3.16 \\
$\mathrm{Ca}^{2+}$ & 3.09 & 3.06 & 2.39 \\
\hline $\mathrm{n}=$ number of measurements
\end{tabular}
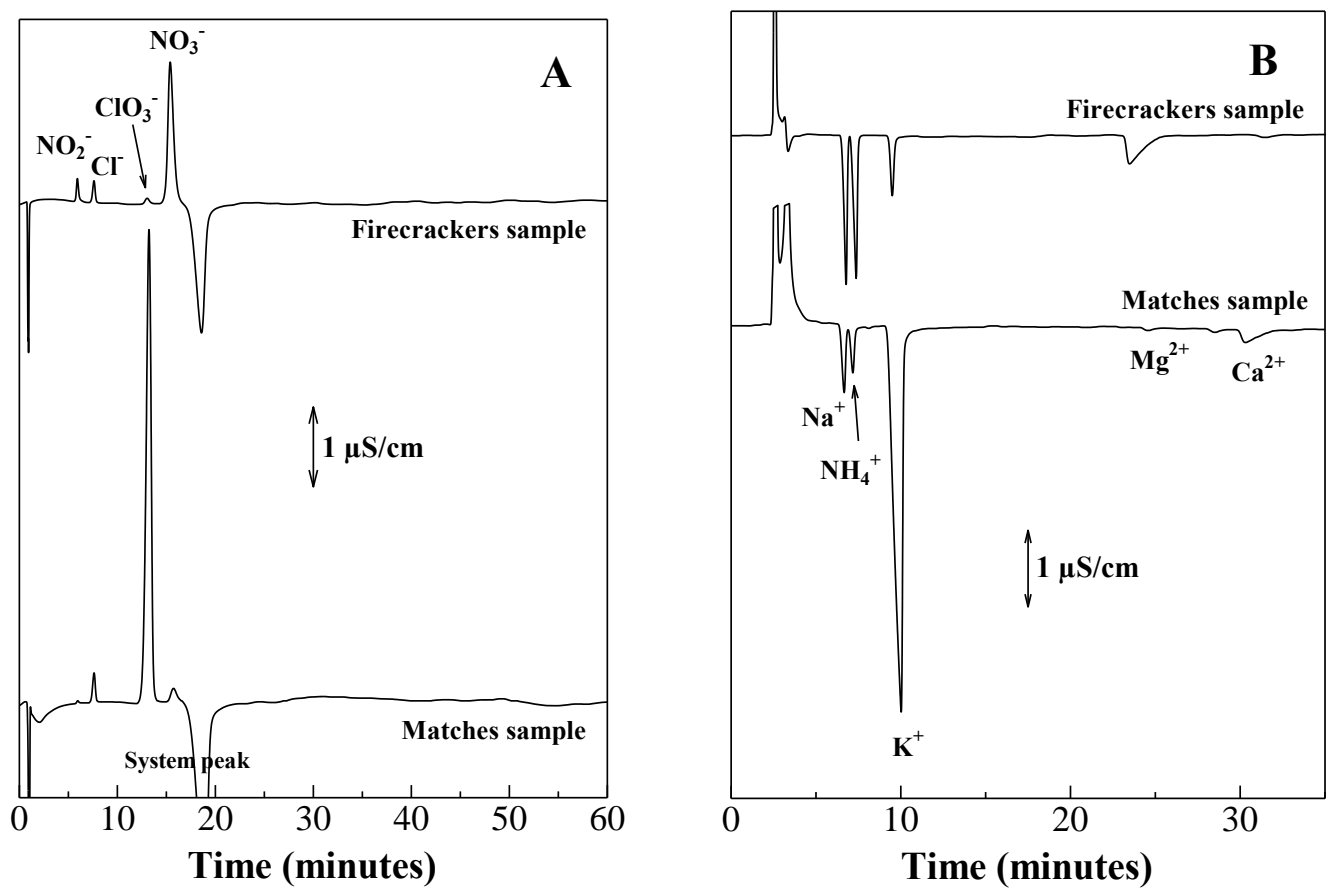

Figure 6. Chromatograms of anions (A) and cations (B) determined in firecrackers and matches samples 


\section{Application to Potentially Explosive Samples}

The present method was successfully applied for simultaneously determining anions and cations in firecrackers and matches samples as known potentially explosive. These samples are available commercially in the market. The samples taken were firecrackers and matches unfired samples have dissolved into deionized water and determined according to the analytical conditions described in Figure 5. To avoid accidental contamination of the samples, each sample was filtered through a $0.45 \mu \mathrm{m}$ of pore size filter membrane before injection into the instrument.

Figure 6 shows the typical chromatograms for both potentially explosive samples. In the firecrackers sample, all ions were detected except $\mathrm{Ca}^{2+}$ and $\mathrm{SO}_{4}{ }^{2-}$ ions. It is expected that $\mathrm{Ca}^{2+}$ and $\mathrm{SO}_{4}{ }^{2-}$ ions are not contained in the raw material used in the manufacture of firecrackers. Therefore, both ions were not found in the detection results. In matches sample, $\mathrm{Mg}^{2+}$ and $\mathrm{SO}_{4}{ }^{2-}$ ions were not detected under this condition. It is also expected that $\mathrm{Mg}^{2+}$ and $\mathrm{SO}_{4}{ }^{2-}$ ions are not contained in the raw material used in matches samples. It is observable that the $\mathrm{K}^{+}$and $\mathrm{ClO}_{3}{ }^{-}$ions levels were the highest concentration. Therefore, it should be noted that potassium chlorate is the main compound in matches.

Table 3. Determination results of anions and cations in firecrackers and matches samples $(n=7)$ using the developed method

\begin{tabular}{cllll}
\hline \multirow{2}{*}{ Analytes } & \multicolumn{3}{l}{ Firecrackers } & \multicolumn{3}{l}{ Matches } \\
\cline { 2 - 5 } & $\begin{array}{l}\text { Mean value }(\mu \mathrm{g} / \mathrm{mL}) \\
(\%)\end{array}$ & $\begin{array}{l}\mathrm{RSD} \\
\mathrm{mM}(\mu \mathrm{g} / \mathrm{mL})\end{array}$ & $\begin{array}{l}\text { Mean value } \\
(\%)\end{array}$ \\
\hline Cations & & & & \\
$\mathrm{Na}^{+}$ & $0.585(13.5)$ & 2.37 & $0.251(5.8)$ & 1.93 \\
$\mathrm{NH}_{4}{ }^{+}$ & $0.659(11.9)$ & 1.92 & $0.206(3.7)$ & 2.75 \\
$\mathrm{~K}^{+}$ & $0.315(12.3)$ & 2.46 & $2.038(79.5)$ & 3.22 \\
$\mathrm{Mg}^{2+}$ & $0.289(6.9)$ & 3.89 & $0.034(0.8)$ & 2.73 \\
$\mathrm{Ca}^{2+}$ & $0.044(1.8)$ & 2.93 & $0.206(8.2)$ & 2.81 \\
\hline $\mathrm{Anions}^{-}$ & $0.499(22.9)$ & 2.45 & $0.055(2.5)$ & 2.46 \\
$\mathrm{NO}_{2}{ }^{-}$ & $0.142(5.0)$ & 2.01 & $0.187(6.6)$ & 2.43 \\
$\mathrm{Cl}^{-}$ & $0.043(3.6)$ & 3.28 & $3.857(322.1)$ & 3.52 \\
$\mathrm{ClO}_{3}{ }^{-}$ & $0.923(57.2)$ & 3.05 & $0.078(4.8)$ & 2.09 \\
$\mathrm{NO}_{3}{ }^{-}$ & ND & & $\mathrm{ND}$ & \\
$\mathrm{SO}_{4}{ }^{--}$ & ND & &
\end{tabular}

Moreover, Table 3 consists of the reproducibility data $(n=7)$ and the determination results for the anions and cations presented in the firecrackers and the matches samples with lower RSD. Therefore, it is suggestable that the present method can be applied as a practical and reference method. 


\section{CONCLUSIONS}

One prominent aspect of the developed method is that the anion- and cationexchange columns are arranged serially via a 10-port valve, performing one pump and one detector for the simultaneous determining of five anions $\left(\mathrm{NO}_{2}{ }^{-}, \mathrm{Cl}^{-}, \mathrm{ClO}_{3}{ }^{-}, \mathrm{NO}_{3}{ }^{-}\right.$, and $\left.\mathrm{SO}_{4}{ }^{2-}\right)$ and five cations $\left(\mathrm{Na}^{+}, \mathrm{NH}_{4}{ }^{+}, \mathrm{K}^{+}, \mathrm{Mg}^{2+}\right.$, and $\left.\mathrm{Ca}^{2+}\right)$ in firecrackers and matches samples which are usually found as potential explosives. The $1.25 \mathrm{mM}$ trimellitic acid mobile phase concentration exhibited good performance in term of the selectivity and sensitivity of anions, particularly $\mathrm{ClO}_{3}{ }^{-}$and cations in both samples. The presented method offered as simple operation and as a reference method, in which it could be applied for routine purposes, especially in the potential explosive samples.

\section{REFERENCES}

Amin, M., Lim, L.W., and Takeuchi, T., 2007. Tunable Separation of Anions and Cations by Column Switching in Ion Chromatography. Talanta 71(4), 1470-1475. https://doi.org/10.1016/j.talanta.2006.07.020.

Amin, M., Lim, L.W., and Takeuchi, T., 2008. Determination of Common Inorganic Anions and Cations by Non-suppressed Ion Chromatography with Column Switching. Journal of Chromatography A 1182, 169-175. https://doi.org/10.1016/j.chroma.2008.01.007.

Amin, M., 2014. Tracing Terrorist through the Determination of Cations and Anions Concentration in Palm Washing Samples Using Ion Chromatography Technique. Indonesian Journal of Applied Chemistry 16(1), 53-61. https://doi.org/10.14203/jkti.v16i1.2.

Doyle, J.M., and Mccord, B., 1998. Novel Electrolyte for the Analysis of Cations in Low Explosive Residue by Capillary Electrophoresis. Journal of Chromatography B: Biomedical Science and Application 714(1), 105-111. https://doi.org/10.1016/S0378-4347(98)00248-5.

Feng, J., Guo, B., Lin, J.M., Xu, J., Zhou, H., Sun, Y., Liu, Y., Quan, Y., and Lu, X., 2008. Determination of Inorganic Ions in Explosives Residues Using Capillary Zone Electrophoresis. Chinese Journal of Chromatography 26(6), 667-671. https://doi.org/10.1016/S1872-2059(08)60031-0.

Grushka, E., and Grinberg, N., 2007. Advance in Chromatography. CRC Press, USA. Vol. 46: $7-12$.

Hopper, K.G., LeClair, H., and Mccord, B.R., 2005. A Novel Method for Analysis of Explosive Residue by Simultaneous Detection of Anions and Cations via Capillary Zone Electrophoresis. Talanta 67(2), 304-312. https://doi.org/10.1016/j.talanta.2005.01.037.

Iskandarani, Z., and Miller, T.E., 1985. Simultaneous Independent Analysis of Anions and Cations Using Indirect Photometric Chromatography. Analytical Chemistry 57(8), 1591-1594. https://doi.org/ 10.1021/ac00285a021. 
Jackson, P.E., Thomas, D., and Chassaniol, K., 2003. Environmental Analysis of Inorganic Anions and Perchlorate by Ion Chromatography. ACS National Meeting Book of Abstracts 222, 3-15. https://doi.org/ 10.1021/bk-2004-0872.ch001.

Johns, C., Shellie, R. A., Potter, O. G., O'reilly, J. W., Hutchinson, J. P., Guijt, R. M., Breadmore, M. C., Hilder, E. F., Dicinoski, G. W. and Haddad, P. R., 2008. Identification of Homemade Inorganic Explosives by Ion Chromatographic Analysis of Post-blast Residues. Journal of Chromatography A 1182(2), 205-214. https://doi.org/10.1016/j.chroma.2008.01.014.

Jones, V.K., and Tarter, J.G., 1984. Single Injection Ion Chromatographic Analysis of Both Anions and Cations. Journal of Chromatography A 312, 456-460. https://doi.org/10.1016/S0021-9673(01)92798-0.

Meng, H.B., Wang, T.R., Guo, B.Y., Hashi, Y., Guo, C.X., Lin, J.M., 2008. Simultaneous Determination of Inorganic Anions and Cations in Explosive Residues by Ion Chromatography. Talanta 76(2), 241-245. https://doi.org/ 10.1016/j.talanta.2008.01.054.

Mishra, M.K., and Jaiswal, G.K., 2017. Analysis of Post Blast Residue Material in Soil Sample for Forensic Consideration. IOSR Journal of Pharmacy and Biological Sciences (IOSR-JPBS) 12(4), 50-52.

Ohta, K., Tanaka, K., and Fritz, J.S., 1996. Non-suppressed Ion Chromatography of Inorganic Anions, Magnesium and Calcium Ions using a Pyromellitate Eluent and Its Application in Evaluating Environmental Water Quality. Journal of Chromatography A 731 (1-2), 179-186. https://doi.org/ 10.1016/00219673(95)01214-1.

Okada, T., and Kuwamoto, T., 1984. Formation Mechanism of Dip Peaks in Nonsuppressed Ion Chromatography. Analytical Chemistry 56(12), 2073-2078. https://doi.org/ 10.1021/ac00276a022.

Saari-Nordhaus, R., and Anderson Jr, J. M., 1991. Simultaneous Analysis of Anions and Cations by Single-Column Ion Chromatography. Journal of Chromatography A 549, 257-264. https://doi.org/10.1016/S0021-9673(00)91437-7.

Weiss, J., 1995. Ion chromatography. $2^{\text {nd }}$ ed., $\mathrm{VCH}$, Weinheim. https://doi.org/10.1002/jhrc.1240190411. 